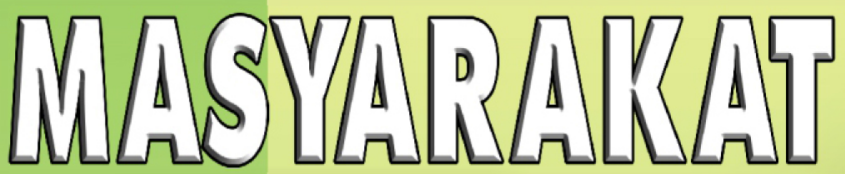

Terakreditasi No. 21/E/KPT/2018
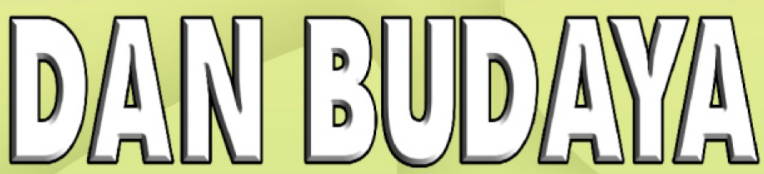

Volume 22 No. 12020

Karakter Keberagamaan di Jawa Pasca Geertz

Gutiono Bayu AJ]

Dayak Kaharingan di Tengah Perubahan Sosial Ekologi dan Praktik Perpindahan Agama dl Perdesaan Kalimantan Tengah

Nindyo Budi Kumoro

MarjinalisasI Hukum Adat pada Masyarakat Adat

The Suartina

Nasionalisme Masyarakat Natuna

Budlana Sotlawan

Frontierisation dan Defrontierisation Sebagal Kerangka untuk Studl Marjinalitas: Kasus Dataran Lindu di Sulawesi Tengah

Greg Acclalo/f dan Muhammad Nasrum

Marjinalisasi Perempuan Kuli Panggul di Pasar Pabean Surabaya

Mitranth Dwi Yuntart

Mencipta Ruang, Menggapal Langit: Pendidikan Publik Kritis dan Ruang Alternatif Minoritas di Yogyakarta dan Bandung Melke Lusye Karrolus dan Firchan Arta Wilaya

Adaptasi Sosial Gay Muslim Indonesia Terhadap Agama dan Keluarga Wisnu Adthariono 


\section{Daftar Isi \\ Jurnal Masyarakat dan Budaya \\ Volume 22 No. 1 Tahun 2020}

Pengantar Redaksi

Halaman

Topik:

iii

Ø5 Karakter Keberagamaan di Jawa Pasca Geertz

Gutomo Bayu Aji

\5 Dayak Kaharingan di Tengah Perubahan Sosial Ekologi dan Praktik Perpindahan Agama di Perdesaan Kalimantan Tengah

Nindyo Budi Kumoro

\5 Marjinalisasi Hukum Adat pada Masyarakat Adat

Tine Suartina

\5 Nasionalisme Masyarakat Natuna

Budiana Setiawan

\5 Frontierisation dan Defrontierisation Sebagai Kerangka untuk Studi Marjinalitas: Kasus Dataran Lindu di Sulawesi Tengah

Greg Acciaioli dan Muhammad Nasrun

§5 Marjinalisasi Perempuan Kuli Panggul di Pasar Pabean Surabaya

Miranti Dwi Yuniarti

\5 Mencipta Ruang, Menggapai Langit: Pendidikan Publik Kritis dan Ruang Alternatif Minoritas di Yogyakarta dan Bandung

Meike Lusye Karolus dan Firdhan Aria Wijaya

\5 Adaptasi Sosial Gay Muslim Indonesia Terhadap Agama dan Keluarga

Wisnu Adihartono

\section{Tinjauan Buku:}

\5 Membicarakan Masyarakat Pinggiran di Indonesia

Riwanto Tirtosudarmo 


\title{
DAYAK KAHARINGAN DI TENGAH PERUBAHAN SOSIAL EKOLOGI DAN PRAKTIK PERPINDAHAN AGAMA DI PERDESAAN KALIMANTAN TENGAH
}

\section{DA YAK KAHARINGAN, IN THE MID OF SOCIAL ECOLOGICAL CHANGES AND RELIGIOUS CONVERSION PRACTICES IN CENTRAL KALIMANTAN}

\author{
Nindyo Budi Kumoro \\ Jurusan Seni dan Antropologi Budaya, Universitas Brawijaya \\ doni.kumoro@ub.ac.id
}

\begin{abstract}
This paper tries to explain the relation between social-ecological change and the phenomenon of religious conversion in a minority group in Indonesia. The case study is the Dayak community religion in Central Kalimantan, Kaharingan, with 'world' or 'official' religions such as Christianity, Catholicism, or Islam. The study of Kaharingan in this paper is placed in the context of Kalimantan as an object of resource expansion with massive intensity by the global economic capitalist chain. Forest exploitation and local gold mining activity from outsiders urged Dayaks to participate in new economic patterns, which caused swidden cultivation to become inaccessible to villagers and began to slowly be abandoned. This has implications for the transformation of the Dayaks in perceiving their relationship with the natural environment, a relationship that was previously the basis of Kaharingan religious beliefs and practices. Based on my ethnographic research in the rural Dayak community upriver Katingan, this paper shows that the religious conversion from Kaharingan to a new religion is more driven by social and economic morals that emphasize individual-household relations rather than the communal-collective pattern as before. This paper also argues that although traditional beliefs have slowly been abandoned, the practice of Kaharingan ceremonies is still held intensively for different purposes.
\end{abstract}

Keywords: minority religion, socio-economic, ecological change, religious conversion

\begin{abstract}
Abstrak
Artikel ini berupaya menunjukkan relasi perubahan sosial-ekologi dengan fenomena perpindahan agama pada kelompok minoritas di Indonesia. Studi kasus dalam tulisan ini adalah agama masyarakat Dayak Kalimantan Tengah, yakni Kaharingan, dengan agama 'dunia' atau 'resmi' seperti Kristen, Katolik, maupun Islam di sana. Kajian mengenai Kaharingan di sini diletakkan dalam konteks Kalimantan sebagai objekdari ekspansi sumber daya dengan intensitas yang masif oleh rantai ekonomi kapitalisme global. Eksploitasi kayu maupun pertambangan lokal dari pihak luar mendorong orang Dayak turut berpartisipasi dalam pola ekonomi baru dan menggeser perladangan berpindah ke posisi yang tidak menguntungkan. Hal ini turut mendorong perubahan orang Dayak dalam memaknai relasi mereka dengan alam sekitar, relasi yang sebelumnya menjadi basis kepercayaan dan praktik agama Kaharingan. Dengan mendasarkan pada hasil riset etnografi perdesaan Dayak di hulu Sungai Katingan, tulisan ini menunjukkan bahwa perpindahan agama dari Kaharingan ke agama baru lebih didorong oleh moral sosial dan ekonomi baru yang menekankan relasi individu-rumah tangga dari pada komunal-kolektif seperti sebelumnya. Tulisan ini juga ingin menunjukkan meskipun kepercayaan lama telah ditinggalkan, namun praktik upacara Kaharingan tetap digelar dengan intensif meskipun untuk tujuan yang berbeda.
\end{abstract}

Kata kunci: agama minoritas, perubahan material-ekologi, perpindahan agama

\section{Latar belakang}

Artikel ini bertujuan untuk mengkaji relasi antara perubahan sosial-ekologi dengan fenomena perpindahan agama lokal (indigenous religion) pada kelompok minoritas di Indonesia. Studi kasus dalam tulisan ini adalah agama masyarakat Dayak Kalimantan Tengah, yakni
Kaharingan, dengan agama 'dunia' atau 'resmi' seperti Kristen, Katolik, maupun Islam di sana. Kajian mengenai transformasi keagamaan orang Dayak seringkali diletakkan dalam konteks inkorporasi dengan institusi negara modern (Schiller, 1997; Baier, 2007; Mahin, 2009); struktur sosial dan politik lokal (Rousseau, 1990; Ardhianto, 2017); persoalan identitas, perubahan 
dan kesinambungan antara agama tradisi dan agama baru (Connolly, 2003; Chua, 2012; Herrmans, 2017); atau intrusi pasar dan perubahan ekonomi (Miles, 1966). Namun belum banyak kajian perpindahan agama di Kalimantan yang melihat dari sudut perubahan alam lingkungan, materialitas, maupun moda mata pencaharian para penganutnya.

Tulisan ini mencoba berkontribusi pentingnya analisis transformasi keagamaan Dayak Kaharingan dilihat dari sudut pandang perubahan materialekologi. Kita tidak bisa menutup mata bahwa beberapa dekade belakangan terjadi perubahan lingkungan yang kian pesat di pedalaman maupun wilayah agraris Kalimantan, tempat kebanyakan penganut Kaharingan tinggal. Pulau Kalimantan sejak paruh kedua abad 20telah menjadi objek ekspansi sumber daya dengan intensitas pertumbuhan yang masif oleh rantai ekonomi kapitalisme global (De Koninck, 2011; Semedi, 2014). Eksploitasi tambang bumi, kayu dan hasil hutan, karet maupun kelapa sawit melalui proses intensifikasi-ekspansi teritorial mengubah lanskap lingkungan secara drastis di segala penjuru perdesaan Kalimantan. Fenomena ini tidak terhindarkan turut mentransformasikan cara hidup masyarakat lokal - dari mata pencaharian sampai pandangan hidup mereka (Arenz.et.al., 2017:14).

Untuk mengajukan argumen di atas, tulisan ini mengambil studi kasus di perdesaan Dayak daerah hulu Sungai Katingan yang merupakan hasil riset etnografis padaantara 2013-2014. Pertanian ladang berpindah yang telah lama dipraktikkan orang Dayak di sana kini tengah berkompetisi dengan kehadiran ekonomi ekstraktif baru,yakni penambangan emas lokal. Bersamaan dengan itu, fenomena perpindahan agama dari Kaharingan ke agama baru (terutama Kristen) mengalami peningkatan signifikan dibanding sebelumnya, meskipun upaya kristenisasi sudah lebih dari satu abad dilakukan di Kalimantan Tengah (Schärer, 1966; Schiller, 1997; Steenbrink, 2008). Perpindahan agama dari Kaharingan seolah bertolakbelakang dengan proses kebangkitan agama lokal ini dengan pelembagaan peribadatan di berbagai penjuru Kalimantan Tengah dalam beberapa dekade terakhir (Baier, 2007; Arenz, 2017).

Maraknya transformasi dari perladangan berpindah ke penambangan emas di hulu Sungai Katingan berimplikasi pada perubahan orang Dayak di sana dalam memaknai relasi mereka dengan lingkungan seperti ladang, hutan, sungai dan sebagainya. Perladangan berpindah selama ini dianggap menjadi pusat sistem kehidupan sosial maupun keagamaan orang Dayak yang secara tradisional ritual-ritual Kaharingan berada di seputar siklus berladang (Miles, 1965; Metcalf, 1981). Dalam kajiannya pada orang Dayak Kantu, Michael Dove (1998:32-33) menyebut ritual dalam perladangan merupakan bentuk aturan moral untuk melakukan pertukaran sosial maupun kosmologis, atau disebutnya sebagai human-spirit exchange. Penggunaan lahan dan tenaga kerja bersama memberikan moral redistribusi kemakmuran dan penjagaan alam milik bersama (komunal) yang disimbolisasi dengan ritual dan upacara keagamaan. Nurit Bird-David (1999:69) menyebut pola ini sebagai sistem relasional, relasi-saling-berbagi yang disakralkan antara komunitas dengan lingkungan sekitar membentuk pengetahuan, termasuk kepercayaan mereka.

Ekonomi ekstraktif dan perubahan lingkungan menyebabkan dasar moral relasional seperti di Kaharingan perlu diorientasikan kembali, tatkala pola tenaga kerja dan lahan tidak dikelola secara bersama,namun dikendalikan masing-masing rumah tangga (individualhouseholds) (Dove, 1985). Perubahan dari sistem relasi kolektif ke individu-rumah tangga dalam unit sosial ekonomi dan keagamaan ini yang akan dijadikan alat analisis, tidak hanya terkait perpindahan agama, namun juga dinamika praktik keagamaan Kaharingan yang justru semakin semarak di hulu Sungai Katingan.

\section{Perubahan Ekologi dan Moral Ekonomi}

Desa-desa Dayak dalam tulisan ini adalah desa yang berada dalam Kecamatan Bukit Raya, wilayah paling hulu Sungai Katingan terletak sekitar 250 kilometer dari ibukota kabupaten (Kasongan), Kalimantan Tengah, atau sekitar 350 kilometer dari Palangkaraya. Areanya berada di sisi selatan Taman Nasional Bukit Raya-Bukit Baka,barisan Pegunungan SchwanerMuller. Akses utama ke wilayah ini hanya bisa dicapai melalui transportasi sungai belasan jam dari ibukota kabupaten, kecuali mendapatkan izin melewati jalan perusahaan konsesi hutan di sana. Kawasan perdesaan Bukit Raya bisa dikatakan salah satu kantong konsentrasi penganut Kaharingan di seluruh Kalimantan (Schiller, 
2007). ${ }^{1}$ Sebanyak $10 \%$ dari penganut Hindu Kaharingan di Kalimantan Tengah tinggal di Katingan, dan lebih dari $60 \%$ populasi Kecamatan Bukit Raya masih memeluk agama ini di samping Kristen, Islam dan Katolik (BPS Kalteng, 2012). Populasi setiap desa di Bukit Raya tidak terlalu besar, berkisar tiga ratus sampai lima ratus penduduk yang mendiami pemukiman memanjang di tepi sungai. Antara satu desa dengan desa yang lain terpisah berkilokilometer di sela-sela hutan primer (tua), bawas (hutan muda bekas ladang), kebun, dan lahan perladangan milik warga desa.

Perladangan berpindah di Bukit Raya seperti halnya dipraktikkan orang Dayak selama ratusan tahun (Seavoy, 1973), yakni membuka hutan dengan teknik tebas, tebang, dan bakar (slash and burn) untuk ditanami padi lahan kering. Di samping aktivitas subsistensi, perdagangan pasar skala kecil juga telah dipraktikkan sejak lama, yakni menjual hewan buruan dan komoditas hutan (terutama rotan) untuk dijual di pasar hilir. Setiap lahan yang dibuka hanya bisa digunakan satu sampai dua musim tanam sebelum mereka membuka lahan baru yang lebih subur. Bawas atau hutan muda bekas ladang jika lama tidak diolah untuk pertanian atau ditanam tanaman keras (cashcrop) maka akan menjadi hutan kembali yang seolah 'dikembalikan ke alam' (lihat, Geertz, 1976). Sistem perladangan ini pada dasarnya mengolah lahan-lahan yang melimpah di hutan, namun hanya dapat memberikan kalori yang minimal karena semata memanfaatkan pembakaran biomasa kayu untuk kesuburannya. Rendahnya produktivitas ladang membatasi jumlah populasi pada orang Dayak ${ }^{2}$ yang kemudian perlu disiasati ketika perladangan memasuki fase pekerjaan berat. Sistem pertukaran tenaga kerja (royong) menjadi strategi mengatasi persoalan ini, setiap rumah tangga saling menyumbangkan tenaga kerja atau bibit padi dan bersama-sama menggarap ladang masing-masing secara bergiliran. Royong juga digunakan untuk keperluan lain,

\footnotetext{
${ }^{1}$ Dalam karya klasik mengenai Dayak Ngaju, Hans Schärer (1963:123) menyebut bahwa kawasan Bukit Raya dianggap sebagai gunungnya para dewa, tempat keramat orang Dayak untuk bertapa dan mendapatkan karohei (jimat) (lihat juga, Mahin, 2009:202).

${ }^{2}$ Di Bukit Raya, rata-rata komposisi rumah tangga berisi 4-5 jiwa (orangtua dan dua anak) meskipun program keluarga berencana pemerintah belum pernah masuk di desa pedalaman ini.
}

seperti pembangunan rumah, pembuatan perahu, maupun ketika sebuah rumah tangga mempersiapkan ritual keagamaan.

Pertukaran tenaga kerja mengikat moral komunalitas orang Dayak sebelumnya. Royong secara sosial menjadi unit produksi utama, sementara rumah tangga hanya berfungsi sebagai unit konsumsi. Ini membatasi mereka untuk memperebutkan tanah atau mengakumulasi hasil panen yang lebih besar dari rumah tangga lain karena pekerjaan pertanian hanya efektif ketika dikerjakan bersama. Hasil ladang dinikmati bersama, resiko perladangan, seperti gagal panen juga ditanggung bersama (Crevello, 2007). Kepemilikan tanah juga bersifat "komunal", dalam arti ketersediaan lahan masih melimpah selama masih berada pada area kampung, tinggal bagaimana cara mengolahnya. Meskipun hak pemakaian eksklusif pada rumah tangga, setiap rumah tangga tidak bisa sesuka hati mengolah tanah karena keterbatasan tenaga kerja yang pada akhirnya harus menyandarkan pada kelompok royong. Maka bangunan sistem relasional orang Dayak memiliki titik tumpu utama pada sistem tenaga kerja dalam perladangan.

Transformasi pertanian ladang di Bukit Raya didorong oleh kehadiran perusahaan konsesi kehutanan (PT. SBK) pada 1970an yang diberikan hak pengelolaan hutan-hutan di sekitar Bukit Raya oleh pemerintah dengan area konsesi lebih dari 250.000 hektar. Tidak lama kemudian hutan-hutan di sana juga ditetapkan oleh pemerintah sebagai Taman Nasional Bukit Raya dan Bukit Baka pada awal 1990an. Sebagaimana sering terjadi, penentuan baik konsesi perusahaan hutan maupun wilayah Taman Nasional acapkali tidak mempertimbangkan aktivitas penduduk sekitar di hutan dan hanya berdasar pemetaan di Jakarta. Baik wilayah konsesi perusahaan maupun Taman Nasional harus steril dari aktivitas penduduk sekitar. Ini menyebabkan lahan hutan yang dapat diolah penduduk untuk berladang menjadi menjadi sangat terbatas.Upaya perusahaan untuk menghentikan praktik perladangan bermacam-macam, mulai program pemberdayaan pertanian intensif (sawah, karet, sayur, dll.) sampai ancaman dari pihak berwajib bagi petani yang masih merambah hutan.

Akhir tahun 1990an perusahaan mengizinkan jalan logging dapat dilewati penduduk, jalan yang membuka akses pasar lebih intensif. Pedagang dari Nanga Pinoh Kalimantan Barat membawa berbagai macam perabot hilir mudik 
ke desa-desa. Penduduk sendiri dengan menumpang truk perusahaan menjual hasil-hasil hutan ke kota tersebut. Pasar tersebut menggantikan pasar di hilir. Integrasi pasar menyebabkan kebutuhan uang tunai meningkat, namun lahan yang semakin terbatas memaksa mencari alternatif, selain berladang. Akses ke kota membuka kesempatan mata pencaharian baru seperti yang sedang marak di perdesaanperdesaan dekat Kalimantan Barat, yakni pembalakan hutan dan penambangan emas. Di kota, penduduk dapat membeli atau mengkredit 'senso' (chainsaw-gergaji mesin) atau 'dompeng' (dongfeng, merk mesin penyedot air).Kondisi ini tidak membutuhkan waktu lama untuk mengubah desa-desa di Bukit Raya pada akhir tahun 1990an menjadi marak pembalakan kayu hutan,baik oleh pendatang maupun oleh penduduk sendiri. Pada pertengahan dekade 2000an, aktivitas pembalakan kayu ini digantikan oleh praktik penambangan emas lokal oleh penduduk karena dirasa lebih menguntungkan dan untuk menghindari kebijakan pemerintah yang menggencarkan razia illegal logging di pedalaman.

Keuntungan dari penambangan emas cukup terlihat jika kita menyusuri desa-desa di sekitar Bukit Raya. Rumah-rumah baru bergaya modern cukup marak dibangun, begitu juga dengan motor baru dan handphone meskipun tidak banyak jalan dan tidak ada sinyal telepon di sana. Mulai banyak anak-anak yang disekolahkan di kota, baik di Kalimantan Barat maupun di hilir Katingan. Saat saya di sana setiap unit tambang emas yang dimiliki penduduk (dengan 4 pekerja) rata-rata menghasilkan 30 sampai 50 gram emas per bulan, memberikan keuntungan bersih 15-20 jutaan/bulan atau enam kali gaji PNS waktu itu. Perladangan tidak sama sekali ditinggalkan, meskipun luas area ladang yang dibuka setiap tahun semakin menurun.

Ekonomi ekstraktif baru ini memberikan kemakmuran baru yang besar, namun juga mengundang resiko sosial-ekologis yang tidak kecil. Pada fase ini royong sudah tidak efektif. Sebagian besar sudah menggunakan sistem upah untuk membayar tenaga kerja ladang, hanya sebagain kecil penduduk menggunakan royong antar-kerabat dekat. Dalam fase membersihkan bawas atau panen yang membutuhkan tenaga kerja banyak, uang tunai akan dibagikan ke pada penduduk yang berpartisipasi royong sebagai kompensasi mengganti waktu kesibukan tetangganya di lokasi penambangan emas.
Penambangan emas ini memiliki resiko merusak ladang-ladang dan mencemari sungai. Penambangan dilakukan dengan mengebor tanah menggunakan air dan mengeluarkan isinya dari perut bumi. Material tanah disaring dengan bahan kimia untuk mendapatkan butir-butir emas. Lahan yang sudah dibor untuk penambangan menjadi rusak dan tandus, dan tidak akan bisa digunakan untuk pertanian ladang kembali. Limbah penambangan dialirkan ke sungai membuatnya menjadi sangat keruh dan tercemar solar dan merkuri. Penduduk di desa-desa mulai meninggalkan Sungai Katingan dan mencari anak sungai bersih yang lebih jauh untuk mandi dan minum.

Warga sering mendengar kabar akan ancaman hukumaparat dan pemerintah daerah yang melarang aktivitas pertambangan ilegal ini. Kabarnya, polisi dapat sewaktu-waktu menangkap siapapun yang kedapatan mengoperasikan unit tambang, meskipun operasi tersebut jarang dilakukan. Rumah kepala desa tidak kalah sibuk hampir setiap hari menggelar sidang adat dan pengambilan sumpah mati (hasapak) dalam menyelesaikan perselisihan pertambangan antarpenduduk. Perselisihan tersebut seringkali menyangkut soal kepemilikan ladang atau tanah untuk menambang. Kini klaim kepemilikan petak lahan di hutan dari masing-masing rumah tangga menjadi sangat penting, disebabkan tidak semua petak lahan dapat ditambang (tidak landai) atau memiliki deposit emas. Tanah menjadi milik eksklusif setiap rumah tangga dan tidak bisa dipertukarkan.

Penduduk desa seringkali menceritakan tentang kesuksesan bisnis ini, sebagaimana tersiarnya kabar salah satu penambang tetangga desa yang mendapatkan emas berpuluh-puluh gram.Namun, tidak jarang juga pergunjingan juga terdengar tentang pemilik unit tambang yang terlilit hutang ratusan juta pada tokeh (juragan) karena lahan tambangnya tidak memiliki deposit emas. Mereka dihadapkan pada situasi untuk memilih, apakah menjadi penambang emas yang makmur, tetapi penuh resiko, atau tetap menjadi petani ladang saja yang bersahaja. Kesempatan menjadi penambang emas sebenarnya terbuka bagi setiap penduduk, karena modal bisa berhutang dari tokeh, dan jika tidak memiliki lahan bisa menyewa ke penduduk lain. Maka dalam menghadapi pilihan ini tidak saja persoalan akses ke mata pencaharian baru (Ribot \& Peluso, 2003), tetapi juga persoalan kultural (livelihood styles-De Jong, 2013) terkait 
bagaimana masing-masing penduduk memaknai resiko dan pandangan hidup untuk masa depan keluarganya.

Hadirnya mata pencaharian ekstraktif baru tidak hanya menghasilkan perubahan ekologi tetapi juga mendorong perubahan moral ekonomi orang Dayak dari komunal-relasional menjadi kompetitif-individual. Masing-masing rumah tangga mencari strategi dan bersaing satu sama lain dalam memanfaatkan situasi di tengah menipisnya deposit emas, ancaman hukum, keterbatasan lahan, kerusakan ekologi, dan kebutuhan tunai yang meningkat. Dalam kasus Bukit Raya, moral kompetitif muncul karena alam lingkungan bukan lagi menjadi sebagai sumber daya yang tidak terbatas untuk dikelola bersama. Dampak transformasi lanskap ini bukan hanya menghasilkan orang yang menang dan kalah dalam kompetisi (Höing \& Radjawali, 2017: 78), tetapi juga melihat alam ekologi sebagai sumber daya yang dapat dieksploitasi (Arenz et al, 2017:18).

\section{Transformasi Kosmologi dan Perpindahan Agama}

Praktik perpindahan agama dari Kaharingan ke agama-agama baru (Kristen, Katolik, dan Islam) di sana secara umum terjadi di desa-desa Bukit Raya, meski dengan intensitas yang berbeda-beda. Berdasarkan data catatan mandor perusahaan di desa, dari sebelas desa di kecamatan ini, Tumbang Samatuan dan Tumbang Karohei menjadi desa yang memiliki intensitas tertinggi perpindahan agama tersebut dalam kurun dua dekade terakhir. Di Samatuan, terjadi peningkatan dari tahun 2008 sampai 2013 terdapat 15 keluarga (sekitar 60 orang jiwa) yang memutuskan berpindah ke agama lain (terutama Kristen Protestan). Jumlah ini tidak terlalu berbeda dengan yang terjadi di Karohei, yakni berkisar antara 15 sampai $20 \mathrm{KK}$ pada periode itu. Bukan kebetulan bahwa kedua desa tersebut juga merupakan wilayah yang paling banyak terdapat praktik penambangan emas - lebih dari separuh penduduknya berpartisipasi dalam penambangan. Musir, Ketua Umat Kaharingan Kecamatan menyatakan bahwa gelombang perpindahan ke Kristen Protestan telah dimulai sejak tahun 1990an sejak jalan perusahaan dibuka dan pendatang dari berbagai latar belakang agama hilir mudik ke desa-desa, meskipun dia mengakui bahwa akhir-akhir ini lebih banyak jumlahnya.
Meskipun yang dikatakan tokoh Kaharingan tersebut ada benarnya, catatan sejarah menunjukkan bahwa besar kecil intensitas pertemuan orang Dayak dengan orang luar telah terjadi sejak berabad-abad silam (Semedi, 2012) - gong dan keramik cina di rumah-rumah kepala Desa Bukit Raya mengatakan hal ini. Maka seharusnya perpindahan agama di daerah ini sudah terjadi sejak lama. Penyebaran Kristen Protestan di Kalimantan sendiri telah dimulai sejak 1830an oleh misionaris Eropadi pedalaman Sungai Kapuas (Schärer, 1966; Schiller, 1997; Baier, 2007; Steenbrink, 2008), dan pertengahan abad 20 kemudian menyebar di berbagai penjuru Kalimantan tempat komunitas-komunitas Dayak. ${ }^{3}$ Di area-area hulu sungai Kalimantan Tengah seperti area Bukit Raya, penyebaran ini didominasi oleh aliran Gereja Kalimantan Evangelis (GKE-Sidang Injil Borneo) yang muncul sejak 1935 dengan gereja yang tersebar luas (Steenbrink, 2008; Arenz et al, 2017). Namun faktanyaagama lokal di area Kalimantan Tengah atau komunitas Dayak Ngaju dapat hidup lebih lama, kuat, dan persisten dibandingkan wilayah lain di Kalimantan maupun Indonesia (van Klinken, 2006:11; Steenbrink, 2008:496). Persistensi ini tidak bisa dilepaskan dari gerakan politik Serikat Kaharingan Dayak Indonesia (SKDI) dari tahun 1951 yang pada 1980an berhasil mengupayakan Kaharingan masuk dalam Hindu Dharma Indonesia (Hindu Kaharingan) dan diakui negara. Pada tataran bawah, keberadaan Kaharingan di bawah payung politik Hindu menyelamatkan penganutnya untuk dicap sebagai tidak beragama, dapat mengurus KTP serta catatan sipil negara, serta tidak perlu pindah ke agama resmi lainnya (Schiller, 1997; Mahin, 2009; Hidayah, 2012).

Namun melihatnya pada aspek politis semata tidak menjelaskan mengapa belakangan Kaharingan tetap ditinggalkan penganutnya seperti di Bukit Raya. Ada baiknya kita perlu kembali mendudukkan bahwa Kaharingan, sebagaimana agama yang lahir dari komunitas lokal sendiri (agama bumi), lebih dominan pada domain praktik dibanding domain doktrin atau dogma dalam membentuk sikap keagamaan penganutnya (Miles, 1966: 112; Schiller, 1996:

${ }^{3}$ Tidak semua wilayah Kalimantan menjadi arena penyebaran Protestan, beberapa wilayah besar mengadopsi Islam (Melanau dan Bakumpai di selatan dan timur) dan Katolik Roma dan Anglikan (Iban dan Bidayuh di barat dan utara) (Großmann, 2017; Ardhianto, 2017). 
412). Domain praktik Kaharingan sendiri tidak bisa dilepaskan dari perladangan sebagai basis material dan sosialnya. Kebutuhan ritual seperti beras, tuak, ayam, babi begitu juga kebutuhan tenaga kerja mempersiapkan acara setiap rumah tangga akan turut ditanggung oleh kelompok royong yang akan dibalas pada saatnya nanti. Ritual, upacara, dan pesta seringkali digelar mengikuti atau berada dalam siklus berladang, mulai dari pembukaan ladang, penanaman padi, sampai panen.

Pada saat pembukaan ladang di Bukit Raya orang akan menggelar ritual nyeriau, meminta izin kepada roh-roh penunggu hutan (gana dan sangiang) apakah tanah tersebut cocok untuk berladang. Prosesi ini ditutup dengan menanam sebuah batu ke dalam lubang tugalan (lubang untuk bibit padi) serta menyembelih ayam di atasnya. Ketika masa perladangan sudah selesai, maka sebelum pesta panen atau bagawi akan digelar ritual mangangkat binyi atau mengangkat batu pusaka yang ditanam ketika awal berladang. Batu menjadi secara simbolik menjadi 'tanda jadi' dari aktivitas perladangan orang Dayak yang "meminjam" hutan untuk dirusak (tebang, bakar, tanam) untuk sementara (Dove, 1998: 31), dan ketika sudah berpindah lahan maka hutan dikembalikan menjadi bentuk semula (bawas atau hutan muda). ${ }^{4}$ Michael Dove (1998:31) menyebut bahwa ini merupakan prinsip tatanan kosmologis orang Dayak di mana terdapat siklus perputaran antara penghancuran dan penciptaan (creation and destruction) terus menerus. 'Perusakan' dari perladangan berpindah pada akhirnya akan menciptakan kembali hutan.

Prinsip lain tatanan kosmologis lain pada orang Dayak adalah kelimpahan kemakmuran memiliki ongkos, dan untuk itu kelimpahan harus didistribusikan. Pesta panen (bagawi) digelar dari sokongan setiap warga desa dan dinikmati dalam waktu satu minggu penuh dengan kelimpahan makanan dan tuak, digelar tari-tarian manasai diiringi karungut(musik Dayak). Pengurbanan babi dilakukan untuk menyatakan terimakasih

${ }^{4}$ Batu juga menandakan penguasaan atau pendudukan antara wilayah manusia dan supranatural, yang tersimbolkan dalam aspek orang Dayak lainnya. Di Bukit Raya, proses pewarisan seorang menjadi balian (dukun) adalah ketika seseorang sakit dan merasa di dalamnya kepalanya tertanam 'batu' ghaib. Setelah menjalani berbagai macam prosesi, batu tersebut kemudian diangkat oleh balian sebelumnya dan seseorang tersebut sah menjadi balian. kepada roh alam atau sangiang. Jane Schneider meneliti kecenderungan ini bahwa orang Dayak bertaruh pada kebutuhan umum, maka perlu melegitimasikan kelimpahan dan peruntungan yang mereka dapatkan, serta untuk mengantisipasi ancaman buruk dan marabahaya sebagai ongkos dari panen raya (Dove, 1998:9). Bagawi juga merupakan mekanisme mencegah akumulasi hasil panen dari beberapa rumah tangga yang merusak norma lokal tentang redistribusi dan resiprositas. Tatkala pekerjaan ladang dikerjakan bersama melalui royong dan hasilnya hanya menumpuk di beberapa keluarga, maka mitos dan kecurigaan akan beredar. Ketika bagawi terlewat dan tidak diselenggarakan pada masa lalu, menurut orang Bukit raya akan menyebabkan pali, semacam kutukan kepada desa, atau 'dosa komunal' (lihat, Schiller, 1997). Bahwa kutukan, kesialan, dan 'dosa' bukanlah urusan individu atau keluarga, namun tertimpakan kepada seluruh penduduk desa.

Selain dalam siklus perladangan, praktik Kaharingan dengan sokongan material maupun tenaga kerja dari royong juga berada pada pengharapan keselamatan hidup sehari-hariatau siklus daur hidup. Ritual tentang keselamatan hidup yakni seperti balian (perdukunan) dan bahajat (selamatan) baru akan digelar ketika terjadi hal yang mendesak seperti sakit dan merasa diganggu gana (makhluk halus), atau peristiwa penting seperti kelahiran, pernikahan, kematian, pembangunan rumah baru, atau sedang memiliki pengharapan hidup. Tradisi upacara terbesar dari Kaharingan, yakni tiwah (ritual penguburan kedua) sangat jarang digelar pada masa lalu karena membutuhkan biaya yang besar (mengurbankan belasan babi/kerbau dan digelar selama seminggu) sehingga sulit untuk disandarkan pada dukungan kelompok royong. Pesta ini biasanya diadakan oleh rumah tangga bangsawan atau elite desa (kepala desa atau tetua adat) yang memiliki ladang luas dan hewan piaraan yang banyak, sekaligus sebagai sarana menegaskan strata sosial tradisional mereka (Miles, 1965:157; Metcalf, 1981:573). Pada rumah tangga Dayak pada umumnya jika tidak berkesempatan menggelar sendiri upacara atau pesta selama satu tahun, maka bagawi atau pesta panen adalah upacara besar yang selalu dapat dinikmati bersama oleh seluruh penduduk desa. Bagawi dan tiwah kemudian menjadi sarana distribusi surplus hasil ladang yang dapat dinikmati bersama. 
Salah satu indikasi memudarnya Kaharingan di Bukit Raya,yakni ketika penduduk sudah jarang menggelar upacara bagawi. Mereka mengingat pesta panen bersama sudah mulai menghilang sejak awal 1990an, disebabkan semakin sedikit warga desa yang terlibat dalam perladangan dan menggunakan ladangnya untuk keperluan lain. Di samping itu semakin banyak penduduk membuka dan mengolah ladangnya dengan membayar (upah) penduduk lain sebagai tenaga kerja. Pesta panen tetap diadakan namun skalanya menjadi lebih mengecil, yakni digelar oleh masing-masing individu rumah tangga sebagai ritual ucap syukur. Perubahan ini berkorelasi dengan periode pembatasan lahan perladangan dari perusahaan dan Taman Nasional, transformasi mata pencaharian ekstraktif, dan integrasi ekonomi pasar dari orang Dayak Bukit Raya.

Ritual yang digelar dalam aktivitas penambangan emas kini memberitahu kita tentang pergeseran relasi kosmologis orang Dayak Bukit Raya alam lingkungan sekitar. Seperti halnya perladangan, dalam memulai penambangan orang akan memilih lokasi dengan ritual nyeriau (nyeriau emas), namun berbeda cara. Jika membuka ladang dilakukan dengan memasang kayu di tanah dan menanam batu, dalam nyeriau emas yakni dengan memukul tanah agar sangiang tahu kalau tanahnya akan ditambang, selain itu juga bermakna mengumpulkan emas di satu titik agar bisa diambil banyak. Jika dalam perladangan nyeriau digunakan untuk izin "meminjam" tanah, pada penambangan nyeriau digunakan untuk izin "meminta" agar bumi yang dikuasainya dibongkar. Jarang pula dalam prosesi ini melakukan pertukaran seperti mengorbankan hewan. Berladang adalah melakukan pertukaran dengan alam/penunggunya, agar ladang dapat digunakan kembali (cultivation), sedangkan menambang adalah mengambil habis (extraction) dari apa yang ada di tanah dan tidak mengharapkan lahan dapat digunakan kembali, sehingga kepada penunggu alam mereka meminta.

Pola di atas juga bisa ditemui pada orang Dayak Bukit Raya yang telah memeluk agama baru. Si Eneng dari Desa Temengai telah beberapa kali sukses membuka lokasi tambang dengan melakukan ritual nyeriau emas. Karena dia telah memeluk Islam, nyeriau yang dilakukan tidak lagi ditujukan kepada sangiang, melainkan nabi kayu, nabi air, dan nabi emas. Saat ritual nyeriau dia tidak memberikan darah ayam maupun tuak, karena haram bagi nabi-nabi yang beragama muslim tersebut. Eneng percaya jika nabi-nabi itu diperlakukan dengan 'baik' sesuai kepercayaannya, maka mereka akan mengizinkan memberikan emasnya kepadanya. Pola 'izin' untuk mengestraksi bumi juga seringkali terdengar dalam doa-doa di gereja desa, kebaktian, maupun dalam ritual lainnya. Seperti halnya salah satu penggalan khotbah pendeta desa di gereja Samatuan berikut;

"Mari saudara, buka Injil Matius ayat lima,
"berbahagialah orang yang lemah lembut,
mereka akan memiliki bumi.' Firman Tuhan
jelas, jika kita meningkatkan kelembutan hati
dan kasih, bumi tanah bisa kita manfaatkan
untuk kesejahteraan kita. Sudah berapa
banyak emas yang saudara hasilkan dari
ladang-ladang kita? Itu hanya sedikit
contoh..."

Dalam konteks perubahan ekologi dan mata pencaharian, agama-agama baru menawarkan diskursus keagamaan yang lebih kaya dalam mengakomodasi praktik ekonomi baru seperti di atas. Maka tidak seperti di dalam Kaharingan, agama-agama baru lebih fleksibel dalam beradaptasi dengan pola ekonomi baru serta tidak memiliki ideologi yang mengakar pada moral relasional secara sosial maupun supranatural. Agama monoteistik seperti Kristen dan Islam memiliki konsensus umum bahwa alam adalah ciptaan dan properti milik Tuhan, namun, begitu kepemilikan ilahi diakui, manusia (yang memiliki hak istimewa di antara penghuni bumi yang lain) memiliki hak penuh untuk menggunakan properti itu untuk keuntungan sendiri (Gottlieb, 2006).

Penjelasan di atas menunjukkan dua tahap perubahan yang berpengaruh terhadap praktik Kaharingan, yakni dari moral komunal desa ke individual-rumah tangga, serta relasinya terhadap alam. Ekonomi ekstraktif membawa implikasi bahwa unit produksi bukan lagi dibentuk secara bersama-sama dalam kelompok royong, tetapi diupayakan dan hasilnya dinikmati oleh setiap individu rumah tangga. Resiko usaha seperti gagal panen bukan lagi menjadi tanggung jawab bersama, namun menjadi beban dari masing-masing keluarga. Setiap ritual yang diadakan tidak lagi perpanjangan dari sistem perladangan, namun menjadi urusan domestik dalam proses perencanaan maupun pembiayaan. Ini salah satunya yang membuat ritual-ritual tradisional menjadi mahal dan merupakan beban bagi rumah tangga yang tidak memiliki biaya.Di 
samping itu, karena prosesnya diupayakan oleh rumah tangga masing-masing, kelimpahan hasil tambang bukan sesuatu yang wajib didistribusikan ke penduduk yang lain. Maka ketika ritual kolektif Kaharingan, seperti bagawi hilang tidak dianggap menyebabkan pali, dan menyebabkan nuansa kepercayaan terhadap roh-roh penunggu alam menurun atau digantikan oleh wujud dari agama baru.

Berhentinya pertukaran sosial dalam ekonomi baru menghentikan pula relasi kosmologis dan spiritual terhadap alam. Dalam situasi ekonomi baru yang kompetitif, hutan, dan lingkungan sekitar bukan sebagai sumber kehidupan yang perlu diolah dan dijaga bersama, namun objek sumber daya yang perlu dipetik sebelum dinikmati yang lain. Alam bukan lagi tempat mereka "meminjam" untuk dikembalikan dalam siklus perputaran kosmologis, namun "meminta" izin mengekstraksi hutan dan mineral di mana tidak ada kewajiban untuk mengembalikan dalam bentuk sedia kala. Maka relasi antara masyarakat dengan roh penunggu alam bukan lagi relasional dan resiprokal, melainkan sebagai objek untuk tujuan keuntungan material.

Dalam kondisi ini, agama baru yang hadir seperti Kristen dan Islam secara ideologis tampak lebih sesuai dibandingkan Kaharingan. Dari diskursus keagamaan yang digunakan, penduduk Bukit Raya sering menemukan legitimasi mereka atas mata pencaharian baru yang dilakukan. Dengan sudut pandang demikian, memudarnya keagamaan Kaharingan di Bukit Raya disebabkan bangunan keagamaan Kaharingan, yakni moral relasional secara sosial maupun kosmologis sudah tidak lagi relevan dalam perubahan ekologi dan ekonomi baru. Penawaran dari Kristen maupun Islam dianggap lebih sesuai pada situasi terkini. Di bawah ini akan dijelaskan bahwa dampak perubahan ekologi di Bukit Raya tidak hanya perpindahan agama, namun juga praktik agama tradisional yang semakin meningkat.

\section{Spiritual Displacement}

Setelah integrasi Kaharingan dengan Hindu pada 1980, terdapat proses pembentukan ulang tubuh keagamaan mereka agar diizinkan dan diakui oleh negara sebagai sebuah agama. Proses inimencakup pembentukan majelis besar Hindu Kaharingan (MBAHKI), membangun rumah-rumah ibadah (balai basarah), kitab suci (panaturan), dan menetapkan hari besar keagamaan
(Baier, 2007: 568-569). Majelis mengkampanyekan perubahan model kepercayaan dan ibadah Kaharingan yang tertulis di Kitab Panaturan yang meniru baik model dalam Kristen maupun Islam (Schiller, 1996: 414). Ibadah basarah dilakukan dengan khotbah pendeta yang diselingi menyanyikan kidung-kidung Kaharingan. Ranying Hatalla Langit ditetapkan sebagai Tuhan tunggal tempat di mana setiap orang mencari jalan keselamatan. Seperti halnya agama monoteis, tata aturan baru ini menekankan relasi langsung dan privat antara seseorang dengan Ranying, nasib baik dan buruk adalah tentang hubungannya dangan Tuhan. Berbeda pada era sebelumnya yang menggunakan pali sebagai prinsip dosa komunal ketika ritualritual tidak dijalankan dengan benar. Majelis Besar menyarankan agar ritual Kaharingan tidak perlu digelar mahal-mahal dan berhari-hari, agar tidak memberatkan penganutnya yang tidak memiliki biaya. Tiwah misalnya hendaknya digelar dengan "pengurbanan kecil", seperti mengganti babi dengan ayam dan cukup satu atau dua hari saja (Schiller, 1996; 1997).

Pengubahan tata cara ini adalah upaya agar Kaharingan menjadi agama yang relevan dengan gerak zaman seperti agama 'resmi' lain. Dogma diperkuat dan fokus peribadatan pada ranah individu, bukan komunitas desa. Praktik ritual Kaharingan yang banyak dan mahal diperkecil dan dibuat sesederhana mungkin agar tidak memberatkan. Ini semua agar Kaharingan tetap survive, tidak ditinggalkan penganutnya, dan tidak dijadikan sasaran proselitisasi oleh Kristen maupun Islam (Mahin, 2009). Namun demikian, dalam kasus Bukit Raya yang terjadi seolah berkebalikan dari harapan, praktik ritual mahal masih dilakukan, dan di sana sini penduduk memeluk agama lain, selain Kaharingan.

Wujud ritual hari ini di Bukit Raya tidak bisa dilepaskan dari transformasi sosial ekonomi yang terjadi, yakni keuntungan menambang emas. Survei penulis di sebuah Desa Bukit Raya menunjukkan dalam lima tahun terakhir ritual berbiaya besar masih sering digelar dan semakin intensif, khususnya pada rumah tangga bermata pencaharian sebagai penambang. Setiap rumah tangga rata-rata mengeluarkan 23 juta rupiah tiap tahunnya untuk pembiayaan ritual Kaharingan. Beberapa rumah tangga kaya seperti tokeh atau penambang dengan lebih dua unit lokasi tambang mengeluarkan biaya dari 50 juta sampai lebih dari 100 juta rupiah untuk membiayai bahajat besar maupun tiwah dengan tujuan antara lain pengharapan anak sukses sekolah, mendapatkan 
untung usaha, maupun ucap syukur. Bahajat 'masuk rumah' adalah upacara yang paling sering digelar, ini dapat dipahami karena banyaknya penduduk membangun atau merenovasi rumah baru dari keuntungan penambangan. Pesta ini minimal mengurbankan tiga babi dewasa, menyediakan makanan, arak maupun tuak untuk seluruh warga desa selama tiga hari dengan biaya rata-rata 15 sampai 20 juta rupiah.

Pesta tiwah merupakan puncak dari gejala ini. Pada intinya ritual ini adalah prosesi mengambil tulang belulang leluhur dari makam untuk disemayamkan dalam sandung atau peti kecil yang didirikan di depan rumah agar arwah leluhur dapat diterima di lewu liau (surga). Si Tomar, pemilik dua unit tambang sekaligus tokeh asal Desa Dahoei yang menggelar tiwah untuk orang tuanya dengan biaya tidak kurang dari 120 juta. Biaya tersebut sebagian besar untuk membeli puluhan babi dan tujuh kerbau untuk kurban serta menyediakan makanan dan tuak selama tujuh hari berturut-turut. Selain Tomar, dalam kurun 2008 sampai 2012 terdapat tujuh keluarga yang menggelar tiwah di Bukit Raya, (satu di Desa Dahoei, tiga di Samatuan, dua di Karohei, dan satunya di Batangkiham). Orang Bukit Raya mengatakan sebelum jaman kerja batang (pembalakan kayu) atau nyedot (penambangan emas), belum tentu setahun ada tiwah di wilayah ini. Pada masa lalu tiwah adalah upacara yang prestisius dan jarang digelar, tidak sembarangan orang bisa menggelar kalau bukan bangsawan atau elite desa (Miles, 1965; Metcalf, 1981). Baik Tomar maupun tuan rumah penggelar tiwah yang lain kebanyakan adalah bukan keturunan kepala, tokoh adat, atau pembuka desa, dalam sejarah keluarganya belum pernah menggelar tiwah sendiri.

Upacara ini membawa desa penuh dengan suasana pesta selama berhari-hari. Makanan melimpah, karungut disko berdentum keras mengiringi orang-orang menari(manasai), dan tuak arak yang terus berputar. Pada tiwah, selama tujuh hari pesta menari nganjan (menari dengan memutari tiang pancang [pantar] hewan kurban) dan manasai dari pagi hingga malam. Berita digelarnya tiwah misalnya akan menyebar ke seluruh penjuru desa-desa, yang membuat tamu yang datang tak hanya warga desa namun juga desa-desa lain bahkan jauh dari kota. Warga desa akan menghentikan aktivitas selama digelar pesta ini, meramaikan acara dan menghormati sang tuan rumah. Si tuan rumah akan sibuk menerima tamu-tamu penting dari tokoh-tokoh desa lain, begitu juga dari pihak perusahaan maupun pemerintah yang biasanya mengirimkan wakilnya. Tuan rumah akan menjadi 'raja' tujuh hari dengan kebanggaan dan prestis luar biasa. Karena nilainya yang tinggi, upacara dan pesta ini seolah menjadi kendaraan bagi tuan rumah untuk meningkatkan status sosial (De Jong, 2013:210) dan memberi kesempatan keluarga "orang bawah" terlegitimasi menjadi kelas atas desa yang sukses. Citra sukses ini penting dalam iklim ekonomi baru yang kompetitif, antara lain memudahkan pemilik unit tambang mendapatkan pekerja. ${ }^{5}$ Dengan sistem bagi hasil, para pekerja tambang pendatang cenderung akan memilih bekerja pada lokasi tambang yang memiliki banyak deposit emas. Faktor-faktor di atas yang memiliki peran besar dalam mendorong tergelarnya pesta upacara Kaharingan di Bukit Raya dari waktu ke waktu.

Ekspresi praktik Kaharingan oleh rumah tangga penambang di atas cenderung berbeda dengan rumah tangga yang memilih tetap menjadi peladang. Secara umum, tidak terlalu banyak ritual dan pesta yang digelar oleh rumah tangga ini dalam lima tahun terakhir, dan ratarata pengeluaran keluarga untuk ritual berkisar 2,5 juta tiap tahunnya. Ketika tidak terdapat keperluan mendesak untuk menggelar balian atau ritual daur hidup, seperti melahirkan, pernikahan, atau kematian, kebanyakan dari mereka biasanya ritual kecil setiap tahun seperti bahajat tahun baru, balian satu malam, ritual ladang, dan nahunan (ritual memberi nama bayi). Ritual yang intens dari kategori rumah tangga ini cenderung memiliki corak 'dahulukan selamat' dan berbiaya kecil, selama saya di sana hampir setiap minggu ada yang menggelar balian yang bertujuan untuk pengobatan maupun ketika merasa kesialan datang ke keluarganya akibat gangguan gana. Ketika tidak ada gangguan tersebut, mereka tidak merasa perlu untuk menggelar ritual-ritual yang mengeluarkan banyak biaya sebagai mana bahajat meminta berkat atau usaha.

Dalam konteks praktik keagamaan, menjadi penganut Kaharingan tetap menjadi beban bagi keluarga yang tidak dapat berkompetisi dalam ekonomi baru. Bagaimanapun menjadi

${ }^{5}$ Ketersediaan pekerja tambang di Bukit Raya yakni dari penduduk desa sendiri maupun pendatang luar desa. Perpindahan pekerja antar pemilik sering terjadi selama para pekerja bebas keluar dari suatu unit ketika satu periode menambang (satu drum solar) telah selesai. 
Kaharingan secara sosial akan dilihat sejauh mereka menggelar ritual-ritualnya yang mahal, bukan dari kepercayaannya. Maka pada titik ini yang dilakukan bukan mengikuti saran dari majelis Kaharingan untuk mengubah skala ritual Kaharingan menjadi kecil (replacement), namun menanggalkan praktik lama untuk sepenuhnya menggunakan praktik baru (displacement) (Robbins, 2014). Si Samun dari Desa Samatuan misalnya mengikuti rombongan keluarga lain yang dibaptis menjadi Kristen Protestan di gereja desa pada tahun 2011. Samun adalah peladang dan perajin tas rotan yang hanya memiliki satu lembar lahan. Dia tidak berani menggadaikan satu-satunya lahan yang menjadi sumber hidup keluarganya, apalagi belum tentu di dalamnya terdapat deposit emas. Alasan personal untuk menjadi Kristen untuk mengubah kondisi kehidupan khususnya sakit punggung dan darah tinggi yang tidak kunjung sembuh. Siapa tahu menjadi Kristen akan sembuh, katanya. Di samping itu, Samun merasa seolah menggelar upacara Kaharingan adalah kewajiban seperti yang marak digelar oleh penduduk lain, padahal ritual semakin mahal dan merepotkan keluarganya yang berpenghasilan kecil. "Iya kalau besok anak-anak saya mampu menggelar tiwah buat saya, kalau tidak kan kasihan bah", keluhnya. Sementara menurut Samun dalam Kristen semua ritual dapat dibungkus dengan kebaktian, termasuk upacara kematian.

Kristen menjadi alternatif kepindahan karena penetrasinya di Bukit Raya dalam keseharian lebih kuat dan menarik dibanding agama lain. Sejak Bukit Raya didirikan sekolah dan didatangkan guru-guru dari Palangkaraya, guru-guru inilah yang membuat kegiatan keagamaan lebih semarak. Secara bergantian beberapa guru diberi amanat untuk mengisi khotbah minggu di gereja karena mereka dianggap lebih pintar dan mengerti soal agama, sementara jarang ada pendeta resmi yang datang. Beberapa kegiatan keagamaan diinisiasi seperti Sekolah Minggu untuk anak-anak dan peringatan paskah maupun natal tahun baru yang diisi dengan perlombaan olahraga, pentas seni, makan bersama, dan khotbah yang dihadiri seluruh warga desa. Ini berkebalikan dengan penetrasi gerakan revivalisme Hindu Kaharingan di sana. Berbeda dari yang terjadi di kota seperti Palangkaraya dan Kasongan, ibadah basarah yang didorong majelis besar desa-desa di Bukit Raya sama sekali tidak mendapat tanggapan dari penduduk. Tidak ada kegiatan yang jelas dari
Majelis Kaharingan Desa, meskipun mendapat dana dari MBAHK. Balai basarah di beberapa desa kosong dan kebanyakan tidak terpakai. Bahkan ada satu basir Kaharingan yang telah ikut berpindah ke Kristen.

Citra Kristen yang lebih efisien seperti yang dikatakan Samun tidak demikian dengan si Tomar dan para penyelenggara tiwah lain. Dalam KTP mereka masih tertulis Hindu Kaharingan dan belum memiliki niat untuk memeluk Kristen, seperti beberapa warga lain. Bagi para penambang emas yang sukses, Kaharingan bukanlah sebagai beban dan masih menjadi kepercayaan yang mereka pegang. Walaupun demikian, kadangkala perpindahan agama ini dilakukan sebagai suatu strategi dihari depan. Ketika telah berpindah Kristen secara adat mereka telah melepaskan beban dan tanggung jawab untuk menggelar upacara Kaharingan yang memakan banyak biaya, namun ketika mereka mempunyai uang, ritual meriah digelar sebagai sarana untuk menaikkan status sosial keluarga. Penggunan upacara Kaharingan untuk keperluan ini cukup relevan tatkala melihat situasi perdesaan pedalaman di Bukit Raya yang tidak mudah untuk membelanjakan barang-barang konsumsi dalam jumlah besar.

Perpindahan ke agama baru dari beberapa penduduk Bukit Raya bukan hanya menghasilkan perubahan ranah praktik. Kepercayaan mereka terhadap sangiang dan gana yang menghuni alam sekitar turut dimodifikasi dalam kerangka Kristen maupun Islam. Di samping para penunggu bumi berubah menjadi nabi-nabi Islam seperti yang dikatakan Eneng, gana juga kini mendapat sebutan sebagai 'iblis' yang bisa ditaklukan atas kekuatan gereja atau Tuhan Yesus bagi penduduk Kristen. Kepercayaan dalam Kristen tidak mengharuskan penganutnya untuk memanggil sangiang dengan mengurbankan ayam, babi, atau menyediakan makanan yang banyak ketika keluarga tertimpa kemalangan. Pandangan Kristen setelah hidup memberi alternatif orang Bukit Raya untuk tidak menggelar tiwah karena setelah meninggal roh akan langsung terbang menuju akhirat.

\section{Penutup}

Penjelasan di atas menunjukkan bahwa iklim kompetisi ekonomi baru dan perubahan pandangan ekologisorang Dayak menurunkan kolektivitas sosial dalam menyokong setiap tergelarnya ritual-ritual Kaharingan. Terdapat 
perubahan moral relasional bawah alam lingkungan bukan lagi dimaknai sebagai mahkluk di mana mereka harus berbagi secara resiprokal, tetapi menjadi sumber daya yang dapat dieskploitasi dan diakumulasi keuntungannya. Hal ini menempatkan masing-masing rumah tangga menanggung beban ritual tradisional yang mahal. Pada titik inipraktik Kaharingan sangat berhubungan dengan siapa yang menang dan kalah dalam transformasi ekonomi di Kalimantan. Fenomena maraknya orang Bukit Raya meninggalkan Kaharingan dengan memeluk agama lain mungkin bisa dilihat sebagai jalan untuk semata menghindari beban tradisional (Miles, 1966; Steenbrink, 2008), namun yang lebih penting secara ideologis Kaharingan sulit untuk direlevansikan dalam situasi hari ini. Hadirnya kemakmuran, seperti kita lihat, menjadi sumber daya yang menguatkan praktik-praktik Kaharingan menjadi lebih intensif, meskipun pesta dan upacara kepercayaan ini cenderung menjadi semacam potlatch untuk menegaskan maupun memperbaiki citra dan status sosial bagi orang yang sukses dalam menambang.

Tulisan ini ingin menunjukkan bahwa dinamika dan perpindahan agama pada kelompok maupun agama minoritas di Indonesia tidak hanya disebabkan oleh subordinasi sosial politik, identitas, maupun proses modernisasi global. Akan tetapi faktor perubahan material-ekologi dan eksploitasi sumber daya baru di tempat di mana kelompok tersebut tinggal juga memiliki peran besar.

\section{Daftar Pustaka}

Ardhianto, Imam (2017). The Politics of Conversion: Religious Change, Materiality and Social Hierarchy in Central Upland Borneo, The Asia Pacific Journal of Anthropology, 18:2, 119-134, DOI: 10.1080/14442213.2017.1280842.

Arenz, Cathrin, Michaela Haug, Stefan Seitz and Oliver Venz (2017). Dayak Societies in Transition - Balancing Continuity and Change. In Cathrin Arenz et al (Eds.) Continuity under Change in Dayak Societies (Edition Centaurus - Sozioökonomische Prozesse in Asien, Afrika und Lateinamerika). Germany: Springer VS.

Badan Pusat Statistik (BPS) Kalimantan Tengah, (2012). Kalimantan Tengah Dalam Angka 2012, Palangkaraya: BAPPEDA
Kalimantan Tengah dan BPS Kalimantan Tengah.

Baier, Martin (2007). "The Development of the Hindu Kaharingan Religion: A New Dayak Religion in Central Kalimantan," dalam Anthropos, Bd. 102, H. 2. (2007), pp. 566-570.

Bird-David, Nurit (1999). "Animism" Revisited: Personhood, Environment, and Relational Epistemology. Current Anthropology, Vol. 40, No. S1, Special Issue Culture A Second Chance? (February 1999), pp. S67-S91.

Chua, Liana (2012). The Christianity of culture: conversion, ethnic citizenship, and the matter of religion in Malaysian Borneo. United States: Palgrave Macmillan.

Connolly, Jennifer (2003). Being Christian and Dayaks; Study Chistian Conversion in East Kalimantan. Ann Arbor: ProQuest Information and Learning Company.

Crevello, Stacy (2004). "Dayak Land Use Systems and Indigenous Knowledge," dalam J. Hum. Ecol., 16(2): 69-73 (2004).

de Jong, Edwin (2013). Making a Living between Crises and Ceremonies in Tana Toraja: The Practice of Everyday Life of a South Sulawesi Highland Community in Indonesia. Leiden \& Boston: Brill.

De Koninck, Rodolphe (2011). Southeast Asian Agriculture Expansion in Global Perspective. In Radolphe De Koninck, Stephane Bernard, and Jean F. Bissonnette (Eds), 2011, Borneo Transformed; Agricultural Expansion on the Southeast Asia Frontier, Singapore: NUS Press.

Dove, Michael R. (1985). Swidden Agriculture in Indonesia: The Subsistence Strategies of the Kalimantan Kantu', New York: Mouton.

Dove, Michael R. (1998). "Living rubber, dead land, and persisting systems in Borneo; Indigenous representations of sustainability," dalam Bijdragen tot de Taal-, Land- en Volkenkunde 154 (1998), no: 1, Leiden, Hlm. 20-54.

Geertz, Clifford (1976). Involusi Pertanian: Proses Perubahan Ekologi di Indonesia. Jakarta: Bhratara Karya Aksara.

Gottlieb, Roger S. (2006). Introduction: Religion and Ecology - What Is the Connection 
and Why Does It Matter?. In Roger S. Gottlieb (Ed) The Oxford Handbook of Religion and Ecology. Oxford Handbooks Online, Online Publication Date: Sep 2009 DOI: 10.1093/oxfordhb/97801951 78722.003 .0001

Großmann, Kristina (2017). The (Ir)Relevance of Ethnicity among the Punan Murung and Bakumpai in Central Kalimantan. In Cathrin Arenz et al (Eds.) Continuity under Change in Dayak Societies (Edition Centaurus - Sozioökonomische Prozesse in Asien, Afrika und Lateinamerika). Germany: Springer VS.

Herrmans, Isabell (2017). Values in Practice: Change and Continuity in Luangan Ritual Performance. In Cathrin Arenz et al (Eds.) Continuity under Change in Dayak Societies (Edition Centaurus Sozioökonomische Prozesse in Asien, Afrika und Lateinamerika). Germany: Springer VS.

Hidayah, Sita (2012). The Politics of Religion The Invention of "Agama" in Indonesia. Kawistara Vol. 2 No.2, 17 Agustus 2012 Hlm.105-224.

Mahin, Marko (2009). Kaharingan: Dinamika Agama Dayak di Kalimantan Tengah, Depok: Disertasi Program Pasca Sarjana Fisip UI.

Metcalf, Peter (1981). "Meaning and Materialism: The Ritual Economy of Death," dalam Man, New Series, Vol. 16, No. 4 (Dec., 1981), 563-578.

Miles, Douglas (1965). "Socio-Economic Aspects of Secondary Burial," dalam Oceania, Vol. 35, No. 3 (Mar., 1965), pp. 161-174.

Miles, Douglas _(1966). "Shamanism and the Conversion of Ngadju Dayaks," dalam Oceania, Vol. 37, No. 1 (Sep., 1966), pp. 1-12, Oceania Publications, University of Sydney.

Ribot, Jesse, C., \& Nancy Lee Peluso (2003). “A Theory of Access,". Rural Sociology 68(2), 2003, pp. 153-181.

Rousseau, Jerome (1990). Central Borneo: Ethnic and Social Life in a Stratified Society, Oxford: Clarendon Press-Oxford.

Schärer, Hans. (1963). Ngaju Religion; The Conception of God Among A South Borneo People. Netherlands: KITLV Martinus-Nijhoff.
Schiller, Anne (2007). "Activism and Identities in an East Kalimantan Dayak Organization" dalam The Journal of Asian Studies / Volume 66/Issue 01/February 2007, pp $63-95$.

Schiller, Anne (1997). Small Sacrifice: Religious Change and Cultural Identity among the Ngaju of Indonesia. Oxford University Press: New York.

Schiller, Anne (1996). "An "Old" Religion in "New Order" Indonesia: Notes on Ethnicity and Religious Affiliation" dalam Sociology of Religion, Vol. 57, No. 4 (Winter, 1996), pp. 409-417.

Robbins, Joel (2014) How Do Religions End? Theorizing Religious Traditions from the Point of View of How They Disappear. Cambridge Anthropology 32(2), Autumn 2014: 2-15. Cambridge Anthropology, doi:10.3167/ca.2014.320202.

Seavoy, Ronald, E. (1973, 1973b). "The Shading Cycle in Shifting Cultivation" dalam Annals of the Association of American Geographers, Vol. 63, No. 4 (Dec., 1973), pp. 522-528.

Semedi, Pujo (2012). Efektifitas pemetaan partisipatoris dalam menjaga kepentingan masyarakat desa-studi kasus tiga desa di sekitar wilayah kerja PT.SBK Kalteng Blok Seruyan-Katingan. In: Working paper. Department of Anthropology UGM Yogyakarta.

Semedi, Pujo (2014). Palm Oil Wealth and Rumour Panics in West Kalimantan. In Forum for Development Studies, DOI: 10.1080/08039410.2014.901240.

Steenbrink, Karel (2008). Chapter Twelve: Kalimantan or Indonesian Borneo. In Jan Sihar Aritonang and Karel Steenbrink (Eds), A history of Christianity in Indonesia. Leiden and Boston: Brill.

van Klinken, Gerry (2006). "Colonizing Borneo: State-Building and Ethnicity in Central Kalimantan," dalam Indonesia, No. 81 (Apr., 2006), pp. 23-49. 